\section{Short-term memory and acoustic similarity}

JACK A. ADAMS, HOWARD I. THORSHEIM, ${ }^{2}$ and JOHN S. MCINTYRE, ${ }^{3}$ University of llinois, Urbana, Ill. 61801

In a STM paradigm, four groups of $96 \mathrm{Ss}$ each had all combinations of low and high acoustic similarity of items and sequential and simultaneous modes of presentation. Acoustic interference occurred as a proactive inhibition effect of prior items, and then only for the sequential mode and an immediate retention test. Acoustic interference was absent at a 30-sec test, showing its short life.

Adams, Thorsheim, \& McIntyre (in press) found that acoustic interference in short-term memory (STM) was a reliable effect at an immediate retention test with sequential presentation of items but absent or a minor effect at longer intervals regardless of presentation mode. Similarly, Conrad (1967) reported acoustic errors at the 0 -sec test which shifted to random errors at a $10-\mathrm{sec}$ test. If acoustic interference is short-lived, its role in memory theorizing (e.g., Adams, 1967) will need adjusting. This experiment asks further about variables for acoustic interference.

\section{GENERAL PROCEDURES FOR ALL GROUPS}

The apparatus was the VI (variable interval) memory drum which uses a paper tape reader to control presentation time. At the beginning of a trial the word "Ready" appeared in the drum's window for $2 \mathrm{sec}$, followed by the item. The items were consoniant tetragrams, and the mode of presentation was either sequential or simultaneous. An item's presentation time was $2 \mathrm{sec}$ for both modes, and $\mathrm{S}$ studied silently. In the sequential mode each of the four letters was displayed for $.5 \mathrm{sec}$, and in the simultaneous mode the letters were displayed together for $2 \mathrm{sec}$. The retention interval then began and $S$ read lines of random digits aloud and as fast as possible until an asterisk signaled recall. The digits were displayed in a line of 15 and changed every $3 \mathrm{sec}$ to insure that $\mathrm{S}$ would not finish a line and have empty time for rehearsal. When the retention interval was zero the asterisk immediately followed the item. The asterisk remained showing for $10 \mathrm{sec}$, during which time $\mathbf{S}$ attempted his recall in writing. Next appeared the words "Recall Aid" for $10 \mathrm{sec}$ which required $S$ one. to report his idiosyncratic association, or natural language mediator (NLM) as it is called, which he used in learning the item (Groninger, 1966; Kiess, 1968; Adams, Thorsheim, \& Mclntyre, in press). If $S$ had no NLM he reported "Rote." The S gave his NLM verbatim but $E$ only checked NLM or Rote on his data sheet. The S was not told that pronouncing the tetragram was an allowable mediator, but $S$ nevertheless would infrequently pronounce the item rather than give a meaningful association and it was tallied as a NLM whenever he did (Lindley, 1966). The instructions gave the general task procedures and described rote and mediated learning without emphasizing either one. Two neutral items were used for demonstration and E illustrated a NLM for each

\section{EXPERIMENTAL DESIGN}

There were four groups, giving all combinations of sequential (Seq) and simultaneous ( $\mathrm{Sim}$ ) presentation mode, and low (L) and high (H) acoustic similarity between the four letters of an item. A $S$ received four trials, each with a different item and a different retention interval of 0 , 5,15 , and $30 \mathrm{sec}$. Each of the four items and each of the four intervals appeared equally of ten in the four trial positions.

The data of Conrad (1964) was used to choose an acoustically similar set of consonants (BCDGPTVZ), and an acoustically dissimilar set (FHJRLNWY) whose letters were acoustically dissimilar to each other and the acoustically similar set. In defining the four items of a set, the eight letters were each used twice and never twice in the same position.

\section{SUBJECTS}

There were 96 Ss in each group, 24 for each trial/retention interval combination within a group. They were university students, both men and women.

\section{RESULTS}

Analysis focused on Trials 1 and 4 and the 0 - and $30-\mathrm{sec}$ intervals, with number of letters in their correct position as the

Table 1

Per Cent Letters Correct for Each Group

\begin{tabular}{lcccccc}
\hline & \multicolumn{5}{c}{ Retention Interval } \\
\cline { 2 - 6 } Group & Trial 1 & 0 Sec & Trial 4 & Trial 1 & 30 Sec & \\
\hline Seq L & 98 & 95 & 27 & Trial 4 \\
Seq H & 89 & 64 & 57 & 29 \\
Sim L & 98 & 92 & 46 & 21 \\
Sim H & 95 & 83 & 75 & 32 \\
\hline
\end{tabular}
for rote items on Trial 1 , and $65 \%$ and $41 \%$ on Trial 4.

Table 1 has the findings (NLM and rotes combined), and retention is very high at the $0-\sec$ test on Trial 1, with the essential equivaleno among groups showing equal input of items regardless of mode and material. At the 0 -sec test on Trial 4 a decrement for $\mathrm{Seq} \mathrm{H}$ was found, however. Analysis of variance for the 0 -sec interval compared $\mathrm{L}$ and $\mathrm{H}$ items, Trials $\mathrm{L}$ and 4 , and Seq and Sim modes. Acoustic similarity and trials were significant main effects $(p<.01)$, but $\mathrm{Seq}-\mathrm{Sim}$ was not. The $\mathrm{t}$ tests between individual group means found none significant on Trial l, but on Trial 4 Seq H was significantly below all other groups which among themselves did not differ significantly.

On the 30-sec test all groups show forgetting, with more of it on Trial 4 than on Trial 1. The same analysis of variance as above was run for the 30-sec test, and all main effects were significant $(\mathrm{p}<.01)$. The $t$ tests on Trial 1 found $\operatorname{Seq} L<S e q H$ and $\operatorname{Sim} \mathrm{L}<\operatorname{Sim} \mathrm{H}, \mathrm{p}<.01$, which is poorer retention for $\mathrm{L}$ items, but this outcome deserves cautious interpretiltion because, for unknown reasons, Groups $\operatorname{Seq} L$ and $\operatorname{Sim} L$ had low NLM production on Trial I. Low recall is an expected consequence. Groups Seq $L$ and Sim L, respectively, had $4 \%$ and $17 \%$ of their items mediated, while Groups Seq $H$ and Sim $H$ had mediation levels of $46 \%$ and $62 \%$. The comparisons of individual group means on Trial 4 all lacked significance.

\section{DISCUSSION}

Our data produce three main findings for acoustic interference. First, acoustic interference has a short life. It was strong on the 0 -sec test for Trial 4 and absent on its $30-\mathrm{sec}$ test. Second, the absence of acoustic effects on the $0 \cdot \sec$ test of Trial 1 and its presence on Trial 4 shows that acoustic interference is an interitem proactive inhibition (PI) effect, not an intraitem effect. If interference was

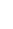

measure. The NLM-rote classification gave a replication of established results and was not included in the analyses. Mediation was positively related to recall, with letters correct over all groups and retention intervals being $81 \%$ for mediated and $58 \%$

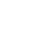


between letters within an item we would have expected it on the 0 -sec test of Trial 1, but it did not appear until Trial 4 Third, acoustic interference depends on the Seq mode. The presentation mode may be a determiner of associative strength and the Seq mode, producing less of it than the Sim mode, is at the low levels of associative strength where acoustic interference is supposed to operate in STM before its transition to long-term memory (Adams, 1967, p. 139). The Sim mode has all the letters and their correct order fully available for rehearsal and mediation throughout the learning period, and these advantages are lacking for the Seq mode. The STM task that most commonly shows acoustic interference in the literature is the Seq mode, immediate recall, and average recall taken over a series of trials where Trial 1 has small weight relative to later trials, and this is consistent with our finding that acoustic interference occurred on the a-sec test of Trial 4 for the Seq mode.

All groups on Trial 1 showed forgetting over $30 \mathrm{sec}$, which is consistent with Experiment 1 of Keppel \& Underwood (1962) and creates discomfort for the interference theory of forgetting because the source of interference is not evident. Keppel and Underwood surmised that extraexperimental interference affects first items when associative strength is weak enough, although the failure of extraexperimental interference to earn empirical support (Adams, 1967, Chap. 7) makes our two practice items a more likely source of PI. The decay theory of forgetting can painlessly explain Trial 1 forgetting, but the greater forgetting on Trial 4 is more consistent with interference theory and the role it gives PI. A more difficult explanatory task for interference theory is the loss of acoustic interference from 0 to $30 \mathrm{sec}$.

\section{REFERENCES}

ADAMS, J. A. Human memory. New York: McGraw-Hill, 1967.

ADAMS, J. A., THORSHEIM, H. 1., \& McINTYRE, J. S. Item length, acoustic similarity, and natural language mediation. Journal of Experimental Psychology, in press.

CONRAD, R. Acoustic confusions in immediate memory. British Journal of Psychology, 1964, $55,75-84$.

CONRAD, R. Interference or decay over short retention intervals? Journal of Verbal Learning $\&$ Verbal Behavior, 1967, 6, 49-54.

GRONINGER, L. D. Natural language mediation and covert rehearsal in short-term memory. Psychonomic Science, 1966, 5, 135-136.

KEPPEL, G., \& UNDERWOOD, B. J. Proactive inhibition in short-term retention of single items. Journal of Verbal Learning \& Verbal Behavior, 1962, 1, 153-161.

KIESS, H. O. The effects of natural language mediators on short-term memory. Journal of Experimental Psychology, 1968, 77, 7-13.
LINDLEY, R. H. Words and pronunciation as coding aids. Psychonomic Science, 1966, 6, 395-396.

\section{NOTES}

1. This research was supported by Grant No.
USPH MH-12022 from the U.S. Public Health Service. Thomas $O$. Nelson assisted in the experiment.

2. Now at St. Olaf College.

3. Now at the University of Manitoba.

\section{Comments on "Experience with congrulty in the perception of incongrulty"}

\section{LAUREN HARRIS, Michigan State Univer- sity, East Lansing, Mich. 48823}

Lasko \& Lindauer (1968) concluded from their study that recognition thresholds for perception of a trick card were higher than that for normal cards. It is suggested that their conclusion is inappropriate in the absence of basic control measures.

There have been numerous criticisms of tachistoscopic studies of recognition threshold for unusual, rare, emotional, or incongruous stimuli (see reviews by Eriksen, $1958,1960,1962$, and by Neisser, 1967, among others). In light of such criticisms, Lasko \& Lindauer's (1968) conclusions about their attempt to replicate Bruner \& Postman's (1949) study of recognition thresholds for incongruous play ing cards are rather surprisingly forthright.

The gist of these criticisms would suggest that the basic phenomenon itself-Bruner \& Postman's finding that recognition thresholds for incongruous playing cards were higher than those for congruous, i.e., real, playing cards-may have nothing whatever to do with "recognition threshold." Interpretation of this finding is made no less difficult for its having been replicated 19 years later.

The critical literature raises a number of questions; for instance, as Neisser (1967, p. 118) puts it, "Do variables such as expectancy and experience [in the current case this would be experience with congruous playing cards] affect 'perception,' or do they just create biases? Can these factors determine what people see or only what they say? [emphases Neisser's]." In the Lasko \& Lindauer case, it would seem that the only empirically justified conclusion is that "volunteer Ss" took longer to verbally report that they had recognized a trick card-the four of hearts in black-than any of the four normal playing cards. Just as the S may quite deliberately refrain from reporting taboo ("dirty") words lest he be thought "dirty-minded" (cf. Postman, Bronson, \& Gropper, 1953; Lacey, Levinger, \& Adamson, 1953; Freeman, 1954, 1955), so in the present case might he have refrained from reporting an "impossible" card lest he be thought naive. Presuming one could control for experience with playing cards, it would be interesting to see whether a S's concern for being perceived as "card-wise" is related to his tendency to report an impossible card. In this connection it would be important to know more about Lasko and Lindauer's Ss. If, as is possible, they were college students, they may value skill with playing cards more than do people from noncollege populations.

Lasko and Lindauer might have included a control group told in advance which cards would be presented and then given the series of tachistoscopic exposures. These Ss would be instructed to report only the figures that they were certain they perceived on each. trial and no others. The threshold would not be defined by the trial on which they could identify the card, since they would already know which card it was, but by the point when they could identify all of the figures on the card. When Haber (1965) used such a procedure for the presentation of rare and common words, the usual differences in 